\title{
THE COMPETITIVENESS AND SUSTAINABLE ECONOMIC DEVELOPMENT OF TAJIKISTAN REGIONS
}

\author{
- Asimova Mashokhida, Avezov Azizullo Khabibovich, Premysl Pálka, \\ Rakhimi Shakhlo
}

\begin{abstract}
This paper assesses the level of competitiveness of the Tajikistan regions to determine their economic development sustainability, using existing approaches. The research methodology is based on the use of institutional synergy and system approaches, using the method of comparative analysis. The paper analyses domestic and foreign experiences, assessing the sustainable development and competitiveness of the regions. It then provides examples of assessment with the use of different methodologies, and makes conclusions on the advantages of assessing the regions' competitiveness as a tool of sustainable development assessment. An attempt was also made to determine the level of competitiveness of Tajikistan's regions, using existing approaches, and existing assessment methods to assess the competitiveness of the Tajik regions.
\end{abstract}

Keywords: assessment methods, sustainable development, regional economy, regional competitiveness JEL Classification: O18, R11, R58, Q56

\section{INTRODUCTION}

To date, many researchers consider that to assess and group the regions according to their economic status, it is necessary to use a set of indicators to determine the most important economic and social characteristics. Repeated attempts have been made to create a unified system to assess the socio-economic indicators of the regions. However, a general methodological approach, e.g., for the purposes of state regulation of regions' development or for indicators of strategic management at a practical level, has not yet been implemented. At present, the concept and methods of assessing competitiveness at the regional level have been inadequately explored. At the same time, it is the regions that are investment targets in the system of reproduction of material, labour and financial resources.

The main goal of this paper is to provide an overview of assessment methods of regions' competitiveness and sustainable economic development. The research methodology is based on the use of institutional synergy and system approaches, using the method of comparative analysis. The paper analyses domestic and foreign experiences assessing the sustainability and efficiency of area development. It further provides examples of assessment with the use of different methodologies, and the most suitable method of assessing the competitiveness of the Tajikistan regions is identified - the "Pattern" method. 


\section{LITERATURE REVIEW}

The relevance of this work is due, on the one hand, to the great interest in research affecting the assessment of the competitiveness of regions in modern science, and on the other hand, to the insufficient development of this subject. Over the past decades, various systems of statistical indicators have been developed that make it possible to generalize the overall coefficient, taking into account the multiple factors that influence the development of regions. A group of specialists created a generalizing system to analyze the socio-economic development of the region, in which several blocks were singled out: development goals, means of achieving the goals, and development results. The strength of this methodology is a large number of indicators that allow a more systematic and objective assessment of regional socio-economic development. The weakness of the methodology is that it does not provide levels of impact of several regions (Apargin, 1999).

Suspitsyn $(2000,2001)$ proposed a methodology of assessing regional socio-economic development on the basis of statistical data calculated per capita. In addition, indicators such as the level of employment, poverty level, investments for one monetary unit of GRP, labour productivity, and a safety index were employed.

Many attempts have been made to create a more general system that allows calculating a single indicator, for example, the methodology used to calculate the actual size of the GRP monetary unit. The calculations were based on data on the cost of the regional basket. (Shtulberg, 2000). According to this methodology, the adjustment of GRP, taking into account the differences in purchasing power of the monetary unit in the regions, reduces the range of variation. To evaluate social and economic development, another methodology was used that includes basic indicators for nine evaluation units. (Granberg, 2000). Regarding the Tajik conditions of management, this technique is poorly applicable, as it does not take into account many internal features.

Syroezhin (1980) suggested setting up dynamics indicators, and proved that the dynamic characteristics have a certain order, which allows them to be compared with each other even if the analyzed indicators are incomparable in the statistical format. Russian scientists (Andreev, 2008) developed a more extended system of indicators, consisting of a key indicators block and a block of additional indicators. The proposed blocks of indicators characterize the development of the social, economic, and environmental spheres of the region. However, the methodology does not allow for full consideration of many important factors of a region's development, the nature of their influence and interaction among themselves, as well as the prospects for sustainable development.

Komarova (2007) has developed a system of indicators to calculate the integral level of a region's competitiveness, divided into three components: availability and use efficiency of the region's resources, the living standards of the region's population, and investment attractiveness and activity in the region.

Combining a systematic approach to the formation of a set of indicators for a sustainable and competitive region, together with a strategic and integrated approach, Fatkhutdinov (2005) offers 19 indicators divided into two groups. The basis of this methodology is a qualimetric approach with a comprehensive assessment of the impact on the competitiveness of each of the indicators. 
The methods and approaches used to determine the level of social and economic development of regions and assess the effectiveness of managing their development are not exhausted by those described above. Studying the existing methodological approaches of sustainable regional socio-economic system assessment development shows that there is no single generally accepted method. In this case, there are two main focus areas:

1. Construction of the integral generalizing indicator, aggregated on the basis of economic, social and environmental performance.

2. Construction of the private system of indicators, each of them reflecting and measuring the individual aspects of sustainable development.

The list of the regional development sustainability indicators is very broad. The indicators of sustainability of the higher-level systems can serve as indicators of regional sustainability. As for the methods of socio-economic system sustainability assessment, some of them should be paid attention to. Thus, to assess the sustainability of the economy, the World Bank researchers developed a method of calculating the indicator GS (Genuine saving) - "True savings", which determines the country's wealth more broadly than the national accounts. The purpose of this indicator is to provide "the net value of change in the overall range of assets, which are important for development: production assets, natural resources, environmental quality, human resources, and foreign assets." Corrections of gross domestic savings are done in two stages. The first stage is determined by the amount of net domestic savings (NDS) as the difference between gross domestic savings (GDS) and the value of depreciation of produced assets (CFC). In the second phase, the net domestic savings are increased by the amount of spending on education (EDE) and reduced by the amount of depletion of natural resources (DRNR) and the damage caused by environmental pollution (DMGE):

$$
G S=(G D S-C F C)+E D E-D R N R-D M G E
$$

The whole calculation of the amount is taken as a percentage of GDP. The genuine saving approach has advantages over many other types of national calculations, since it provides an opportunity for cross-country comparisons. Regular negative results can be interpreted as a fact of an unstable development of the country which will cause negative effects in the long-term perspective.

The following approach to sustainability assessment was proposed by Yale and Columbia universities for the World Economic Forum in Davos a calculation of the sustainability index (The Environmental Sustainability Index). The index is calculated according to 22 indicators.

Each indicator is determined by averaging 2-5 variables, there are 67 variables in total. Formally, all the variables are given equal weight in the calculation index, since there are no generally accepted priorities in the ranking of environmental problems. "Ten top" most stable countries are: Finland, Norway, Canada, Sweden, Switzerland, New Zealand, Australia, Austria, Iceland, Denmark and the USA. CIS countries took from 35th to 50th places.

Another noteworthy method of calculating index of sustainable economic welfare (Index of Sustainable Economic Welfare) was proposed by Cobb \& Daly (USA) in 1989, and was submitted to European countries (Germany in 1991, Great Britain in 1994, Austria, Scotland, Denmark and 
Netherlands). The index represents the size of GDP per capita, adjusted for the cost of socioeconomic and environmental factors. The development of this index is an attempt to build an index of monetary aggregate, directly comparable with the standards of the national accounting, taking into account the important points which are denied in other methods due to their high aggregation. During the index calculation, the variables such as the cost of water pollution, air and noise pollution, the loss of agricultural land, compensation for future generations for the loss of non-renewable energy sources, and so on, are taken into account.

In some countries, such as USA, UK, Denmark, Portugal while assessing the sustainability of the socio-economic system, a system of measures-indicators is used. One of the most comprehensive indicators of a sustainable development system was developed by UN Commission for Sustainable Development in 1996. The selection of indicators was carried out on the four subsystems - social, economic, environmental and institutional - under the scheme: pressure, state, response. The original list included 134 indicators, and then their number was reduced to 60 .

The system of environmental indicators of the Organization for Economic Cooperation and Development (OECD) is widely recognized in the world. The OECD Model identifies causal relationships between economic activity, environmental and social conditions, which gives more reasonable approach to the development of policy for solving the existing problems of sustainable development.

As another methodological approach of sustainability assessment can be considered the analysis of provision of a socio-economic system with natural resources based on modeling. The world practice shows the attempts of constructing global development models that take into account the influence of complex factors. One of them is a model of «Globesight», which integrates subsystems such as: population (demography), economy (GDP, energy, investments), environment (use of natural resources). The advantage of the model is the ability to forecast the future state, to evaluate the effect of the decisions made, clarity and a wide range of concepts, and so on.

The analysis of existing approaches allows us to conclude that there is no single point of view among scientists in determining criteria of the regional sustainability systems. The achievement of development goals, the system's ability to function and grow is considered by one group of scientists as the criteria of sustainability, by others - the availability of system within the prescribed limits, in the zone of sustainability, and by the third - the balance, and adaptability, etc.

\section{METHODOLOGY}

Researchers and scientists are actively working on the development of sustainable socio-economic system assessment methods. Studying the currently existing methodological approaches of sustainable regional socio-economic system assessment development shows that there is no single generally accepted method. It should be noted that in the 90s of the XX century, an English economist, R. Turner, distinguished a weak and a strong economic sustainability. Moreover, a weak sustainability, he interpreted as the constant time of stock of capital assets, and a strong sustainability ("ecological economics") - as the conservation of the total stock of capital assets, while maintaining the ecological natural capital (Rosenberg, 2000). Russian researchers, Golubeckaya, Makarov and Bovkun (Golubetskaya, 2005), proposed the calculation method 
which is based on the "Hartwick rule", the essence of which is the following: a country with an economy depending on natural resources must reinvest part of the income from their (resources) exploitation to preserve the constancy of a real consumption over time. At the same time, to analyze the region's economic sustainability, there is accepted the concept of weak sustainability indices $-\mathrm{Z}$ and strong sustainability - Z'. Moreover:

$$
Z=(S-D A-D P) / Y
$$

$\mathrm{S}$ - Gross domestic savings;

Y - gross regional product (GRP);

DA - the value of anthropogenic capital depreciation;

DP - the value of natural capital depreciation.

It becomes clear that the main components of sustainability index are the depreciation of anthropogenic capital, natural capital depreciation, and general regional savings. The cost of fixed assets of economic sectors, the level of their depreciation, the share of fully depreciated fixed assets, multiplied with each other - the original data for calculation of the anthropogenic capital depreciation. The depreciation of natural capital is the amount of current expenditure on environmental protection and the cost of natural resources used in the region. In modern society, the value of natural capital $\left(\mathrm{D}_{\text {resource }}\right)$ is determined on the basis of its two components:

$$
D_{\text {resource }}=D 1+D 2
$$

D1 - industrial value of the resources used, i.e. their market price;

D2 - ecological, or natural component (not calculated in Russian).

To simplify the calculation of monetary assessment of used the volume of natural resources in a particular region the indicator of resource intensity of GRP can be used, which is calculated by the following formula:

$$
\text { Dres. = Resource GRP X GRP }
$$

The indicator of total regional savings includes the following: from anthropogenic capital - the size of unworn industrial funds, from the natural capital - investments in fixed capital, directed for the environmental protection and rational use of natural resources.

In its turn, strong sustainability index $\left(Z^{\prime}\right)$ is calculated as the ratio of the amount of natural depreciation and anthropogenic capital to the gross regional product:

$$
Z^{\prime}=(D A+D P) / Y
$$

DA - the value of anthropogenic capital depreciation;

DP - the value of natural capital depreciation;

Y - Gross Regional Product (GRP).

Moreover, the depreciation of natural and anthropogenic capital is nothing but a component of the "net cost" (albeit incomplete) of all final goods and services produced in the region during the analyzed year. 
Thus, we can conclude that the smaller the amount of these types of depreciation per unit of gross regional product, the higher the efficiency of the region's economy. Also, it is useful to take into account a number of requirements when creating a methodology:

- A system of indicators should include all the components of the regional system: economic, social and environmental;

- The number of indicators should be limited;

- Indicators should be comparable.

The dynamics of differences between the regions which is increasing demonstrates the need to create an integral indicator of regional sustainable socio-economic development. The methods of assessing regional sustainability of socio-economic system must include the following steps.

The first step: justification of indicator's composition.

The indicatiors of regional sustainability development are not fixed and set forever. They are determined on the basis of internal factors characterizing the economic, social and environmental development of the regions. In our opinion, the following indicators (Tab.1) can be used to calculate the integral index of sustainability assessment of a regional development system (Tab.1).

Tab.1 - The list of indicators for calculation of the integral indicator of sustainability of a regional socio-economic system. Source: Authors elaboration

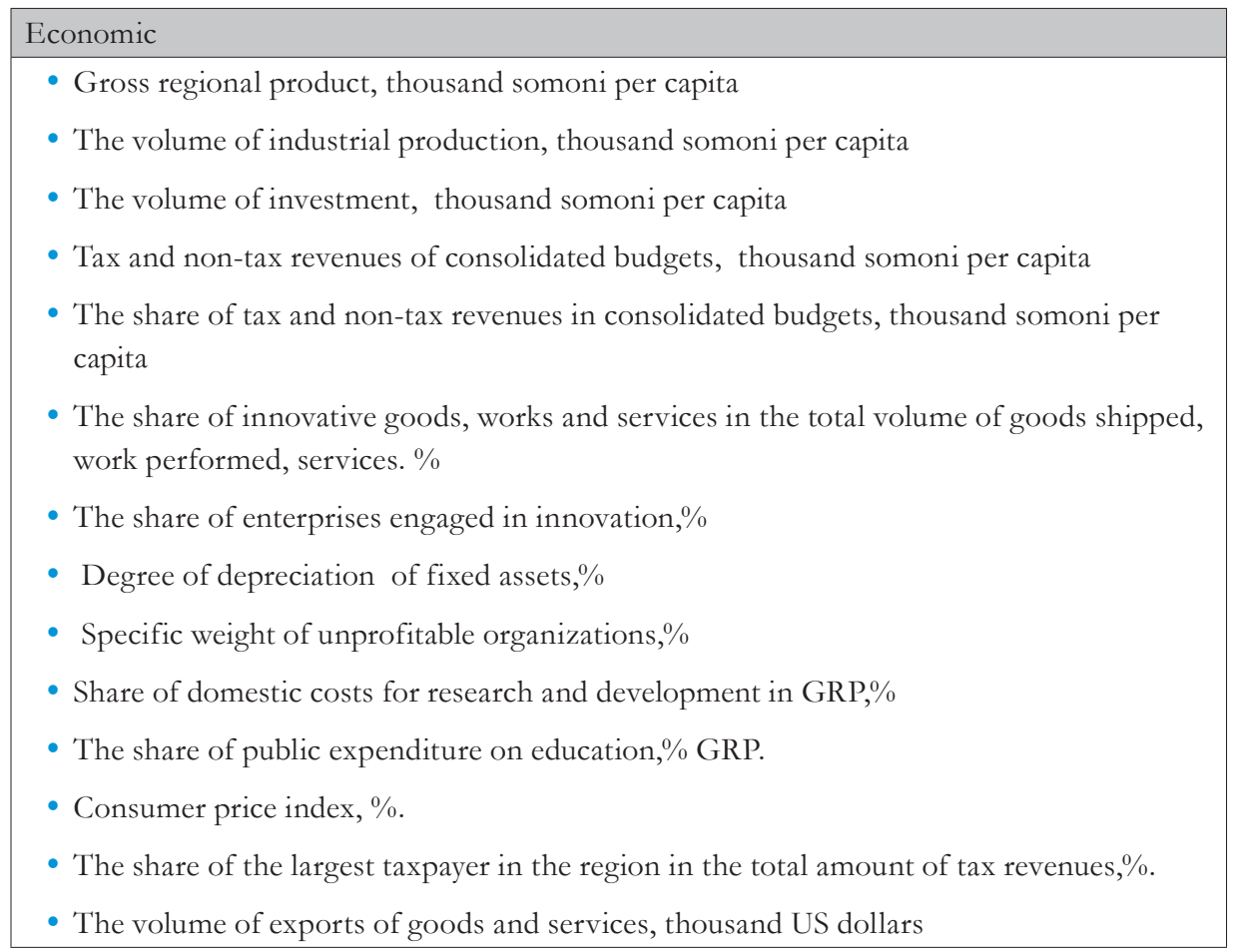


Social

- Ratio of monetary incomes per capita and living-wage, times

- Share of population with incomes below living-wage level, $\%$

- Retail commodity turnover, somoni per capita

- Level of registered unemployment, $\%$

- Level of economic activity of population, $\%$

- The proportion of employed people with higher and incomplete higher professional education, in the total number of employed, $\%$

- Depopulation ratio of population

- The share of dilapidated and emergency housing stock in the total area of the entire housing stock, $\%$

- Number of registered crimes per 100 thousand people

- Birth rate, per 1,000 people.

- Mortality rate per 1,000 people.

- Life expectancy, years.

- Income differentiation ratio.

\section{Environmental}

- Specific weight of the water samples tested, not corresponding to hygienic standards by sanitary and chemical indicators, $\%$

- Specific weight of the water samples tested, not corresponding to hygienic standards by microbiological indicators, $\%$

- Emissions of pollutants into the atmosphere, departing from stationary sources, tons per 1,000 people.

- Areas of green woodlands and plantations in the cities by regions, sq.m per capita

- Reforestation, hectare per 1,000 people.

- The share of government spending on improving the environmental situation in the region, $\%$ of total costs.

- The share of commercial organizations investments in fixed assets aimed at protecting the environment and rational use of natural resources, $\%$ of total investment.

- The share of recyclable and recyclable waste, $\%$.

In our opinion, these indicators are the most informative in assessing the sustainability of regional development. They allow assessing the level of participation of public authorities in regulating the development of the social, economic and environmental spheres of the region, and also identify weaknesses in regional development. Some of the indicators are presented in the form of relative values. This allows a more complete understanding of the level of sustainability 
of the development of the region, avoiding the time-consuming procedure for selecting reference indicators and calculating the integral indicator of sustainability of development.

The second stage: assessment of development level of the region by each indicator. To take into account weighting of the indicators and their difference degree in the levels by regions, and also for calculating a single complex indicator of the development level, it is practical to use the method of multidimensional comparative analysis based on the method of Euclidean distances. It allows considering not only the absolute importance of indicators of each region, but also the degree of their proximity (range) to the benchmark. In this regard, the coordinates of the regions compared are expressed in fractions of the corresponding coordinates of the unit benchmark. ki - assessment of a development level of a region i on each indicator:

$$
\begin{aligned}
& k_{i}=\left(x_{i} / \max \left(x_{i}\right)\right)-\text { direct indicator } \\
& k_{i}=\left(\min \left(x_{i}\right) / x_{i}\right)-\text { reverse indicator }
\end{aligned}
$$

$x_{i}-$ value of indicator in the region $i$;

$\max \left(x_{i}\right), \min \left(x_{i}\right)$ - Indicator-benchmark, which can be optimal (or threshold) values of regional development indicators.

The third stage is the calculation of the complex indicator of sustainability by blocks. Each indicator is squared (to avoid negative values), then the average arithmetic score is found and the square root is extracted:

$I_{j}=\sqrt{\frac{\sum_{i=1}^{n} k_{i}^{2}}{n}}$

$I_{j}$ - a complex indicator of stability by each block of indicators.

The fourth stage is the formation of an integral indicator.

At the same time, an important point is the choice of the form of construction of a generalized index (integrated index) of the sustainability of the regional socio-economic system.

The indicators of sustainable development are most often expressed in the form of arithmetic particular indicators (for example, the index of human development). However, to reflect the significance of each of the considered components of the socio-economic and ecological system, their proportionality corresponds more to the average geometric magnitude. The change in any of the particular indicators leads to a change in the value of the generalizing indicator and fixes the change in the sustainability of the region.

On this basis, the integral sustainability index can be calculated by the following formula:

I sust. $=\sqrt[3]{\text { Iecon } \times \text { Isoc. } \times \text { I }}$ ecol.

Iecon. - economic sustainability;

Isoc. - social sustainability;

Iecol. - environmental sustainability. 
Such a construction of the indicator allows reflecting the significance of each of the components considered the socio-economic and ecological system. The change in any of the particular indicators leads to a change in the value of the generalizing indicator and fixes the change in the sustainability of the region.

The fifth stage is the interpretation of the integral assessment of the sustainability of the socioeconomic development of the region.

For this purpose, threshold values of the sustainability index should be established. The integral sustainability index can be in the range from 0 to 1 . Consequently, six levels of sustainability of the regional socio-economic system can be distinguished, which are united into four sustainability intervals. (Tab.2).

Tab.2 - The interpretation of threshold values of integral index of sustainability of a regional social and economic system. Source: Garkavaya (2015)

\begin{tabular}{|l|l|l|}
\hline $\begin{array}{l}\text { Sustainability } \\
\text { interval }\end{array}$ & $\begin{array}{l}\text { Index interval } \\
\text { boundaries }\end{array}$ & level of system sustainability \\
\hline 1 & $0.9<$ Isus 1.0 & High level of sustainability \\
\hline \multirow{2}{*}{2} & $0.75<$ Isus 0.9 & sustainable development \\
\cline { 2 - 4 } & $0.5<$ Isus 0.75 & Development close to sustainable \\
\hline \multirow{2}{*}{3} & $0.25<$ Isus 0.5 & Development with signs of unsustainability \\
\cline { 2 - 4 } & $0.1<$ Isus 0.25 & Unsustainable, pre-crisis development \\
\hline 4 & $0<$ Isus 0.1 & Absolutely unsustainable development, crisis \\
\hline
\end{tabular}

Interval 1 characterizes a very high degree of sustainability of the system. A system in this interval does not require any corrective influences from the subject of management.

Interval 2 corresponds to sustainable development or close to it. However, factors that reduce the sustainability of the system can accumulate in this zone. The management entity should reduce the impact of these factors.

Interval 3 of the integral index reflects the presence of negative trends of processes that disrupt the equilibrium of the system, and indicates a threat to the security of the system. The management is required to adopt a set of measures aimed primarily at eliminating threats, ensuring sustainable development of the system in the long- term perspective.

Interval 4 of the integral index represents a crisis zone, where qualitatively new processes begin, leading to a complete collapse of the system. The management entity should take urgent anticrisis measures.

The study of modern methods of assessing the competitiveness of the regions allows us to conclude that in many respects, they are based on an assessment of the competitiveness of countries.

Many scientists are actively engaged in developing methods of assessing the competitiveness of the regions, but a unified methodology has not been worked out yet. There are various methods of assessing the competitiveness of regions, based on the basis of statistical indicators, expert assessments, ranks (Shekhovtseva, 2001). 
The evaluation of competitiveness makes sense only if the state of the subject is compared at different times (intervals) of time, or when the subject of study is compared with comparable competitor objects (Seleznev, 1999). There are general and particular indicators of the region's competitiveness. The purpose of using general indicators of the region's competitiveness is to determine the ranking of the region in comparison with other regions. The list of common indicators is established and calculated for all regions. The list of private indicators is selected depending on the specific goals and objectives of the study.

The level of competitiveness of the region can be assessed by applying an integral assessment of the competitiveness of the region studied, comparing it with the integral assessment of the competitiveness of the reference region. As a reference region, it is most expedient to use a particular region (actually existing or conditional) that has the best characteristics of competitiveness (Merkushev, 2004).

An integrated assessment of competitiveness can be obtained on the basis of three private systems of indicators: the region's economic potential, regional efficiency and competitive advantages.

For the synthesis of integral indicators of economic potential, regional efficiency, competitive advantages and directly the level of competitiveness, nonparametric methods of statistical analysis could be used.

The main advantage of using nonparametric methods is to reduce the dimension of matrices of the original data by "compressing" the original information. In this case, non-parametric methods of multidimensional statistical comparisons have little sensitivity to distortions in statistical data, are applicable to small samples, and do not require comparability of the units of measurements of particular indicators.

These shortcomings in the study of the competitiveness of the Sughd region can be eliminated by multidimensional nonparametric methods using relative estimates, for example, using the method of relative differences or the "Pattern" method.

The method of relative differences involves obtaining estimates on partial indices by means of the normalization using formula (10). That is, the excess of the value of the $j$-th partial indicator for the $\mathrm{i}$-th region over the minimum value correlates with the magnitude of the variation of the $j$-th partial index across the aggregate of regions.

$t_{i j}=x_{i j}-x_{j \min } / x_{j \max }-x_{j \min }$

The value of the integral coefficient can be obtained by means of the arithmetic average of the simple partial coefficients, see formula (11). The values of the coefficient will belong to the region $[0 ; 1] .=1$ can be achieved only if the $\mathrm{i}$-th region has the best values for all the particular indicators.

$$
T=\frac{\sum_{i=1}^{n} t i}{\mathrm{n}}
$$

The "Pattern" method allows you to obtain estimates for particular indicators by relating the actual values to the best ones - see formula (4). The value of the integral coefficient is determined by the formula (2). 
$x=x_{i j} / x_{\max }$

Using the method of relative differences and the "Pattern" method involves imposing a restriction on the positivity of the initial values of the private indicators.

results

For the purpose of determining the level of competitiveness of the Sughd region, in our opinion, the use of the "Pattern" method is preferable, since the method of relative differences has the property that reduces its informativity, namely: the coefficient value for the region with the worst value will be zero.

Using the "Pattern" method, it is necessary to perform calculations on the systems of private indicators of economic potential, regional efficiency and competitive advantages. Thus, we obtain estimates of the three components $\left(\mathrm{T}_{\mathrm{pot}}, \mathrm{T}_{\text {eff }}, \mathrm{T}_{\text {adv }}\right)$ needed to determine the integral evaluation of competitiveness, obtained as the arithmetic mean of the estimates.

In addition, this methodology can be improved by using weighting factors for each of the integrated assessments of the competitiveness components of the region.

The performed calculations will make it possible to group the regions according to the level of competitiveness. Being awere that it can take values from 0 to 1 , you can select five groups of regions at equal intervals: 1 group - high level of competitiveness; 2 group - very high level; 3 group - intermediate level; 4 group - low level; Group 5 - non-competitive regions.

On the basis of the statistical data, the calculation of the region's economic potential factors $\left(\mathrm{T}_{\mathrm{pot}}\right)$, regional efficiency $\left(\mathrm{T}_{\text {eff }}\right)$ and competitive advantages $\left(\mathrm{T}_{\text {adv }}\right)$ was carried out. The first group of private indicators reflects the economic potential of the region (Table 3 ).

Tab. 3 - The system of private indicators of the region's economic potential. Source: Authors' calculations

\begin{tabular}{|l|c|c|c|c|}
\hline \multirow{2}{*}{ Indicators } & \multicolumn{3}{|l|}{ Regions of the Republic of Tajikistan } \\
\cline { 2 - 5 } & SR & $\begin{array}{c}\text { Dushanbe } \\
\text { and RRS }\end{array}$ & KHR & GBAR \\
\hline $\begin{array}{l}\text { Average annual number of employees, thousand } \\
\text { people }\end{array}$ & 1 & 0.64 & 0.93 & 0.06 \\
\hline Number of employees in small business & 0.32 & 1 & 0.06 & 0 \\
\hline Area of agricultural land and arable land, ha & 0.30 & 0.08 & 1 & 0.001 \\
\hline Investments in fixed assets, thousand somoni & 0.32 & 1 & 0.99 & 0.07 \\
\hline Gross regional product, thousand somoni & 0.17 & 1 & 0.67 & 0.04 \\
\hline $\begin{array}{l}\text { Number of scientific and educational institutions } \\
\text { performing research and development, units }\end{array}$ & 0.12 & 1 & 0.12 & 0.07 \\
\hline $\begin{array}{l}\text { Number of organizations with participation of } \\
\text { foreign capital issuing products and providing } \\
\text { services, units }\end{array}$ & 0.18 & 1 & 0.02 & 0 \\
\hline
\end{tabular}




\begin{tabular}{|l|c|c|c|c|}
\hline $\begin{array}{l}\text { Number of employees in organizations perform- } \\
\text { ing research and development }\end{array}$ & 0.15 & 1 & 0.11 & 0.08 \\
\hline $\begin{array}{l}\text { Coefficient of the economic potential of the } \\
\text { region }\left(\mathrm{T}_{\mathrm{pot}}\right)\end{array}$ & 0.32 & 0.84 & 0.49 & 0.04 \\
\hline
\end{tabular}

According to the average annual number of employees, the Sughd region takes the leading position, followed by the Khatlon region (0.93), Dushanbe and the RRS (0.64), and the minimum value for the Gorno-Badakhshan autonomous region (a. 06). In terms of the number of people employed in small business, investments in fixed assets, the number of research and educational institutions that carry out research and development, the number of organizations with a foreign capital participation, the number of employees in organizations performing research and development, the Sughd region ranks second, behind only Dushanbe and RRS. According to the area of agricultural land and arable land, the region ranks second after GBAR. The coefficient of the region's economic potential ( $\mathrm{T}_{\text {pott }}$ ) of the Sughd region was 0.32 , which shows the third position after the Dushanbe and RRS (0.84) and Khatlon region - 0.49. GBAR has the lowest coefficient - 0.04. Table 2 shows the calculation of regional efficiency indicators.

Tab. 4 - The system of private indicators of regional efficiency. Source: Authors' calculations

\begin{tabular}{|l|c|c|c|c|}
\hline \multirow{2}{*}{ Private indicators of the region's competitiveness } & \multicolumn{4}{|l|}{ Regions of the Republic of Tajikistan } \\
\cline { 3 - 6 } & SR & $\begin{array}{l}\text { Dushanbe } \\
\text { and RRS }\end{array}$ & KHR & GBAR \\
\hline GRP per capita, somoni & 0.65 & 1 & 0.61 & 0.51 \\
\hline Volume of industrial production per capita, somoni & 0.54 & 1 & 0.65 & 0.12 \\
\hline Monetary income per capita, on average per month & 0.49 & 1 & 0.44 & 0.43 \\
\hline Agricultural output per capita & 0.73 & 0.05 & 0.97 & 1 \\
\hline Volume of exports per capita, USD & 0.67 & 1 & 0.84 & 0.54 \\
\hline Coefficient of regional efficiency $\left(\mathrm{T}_{\text {aff }}\right)$ & 0.51 & 0.68 & 0.59 & 0.43 \\
\hline
\end{tabular}

According to the GRP per capita, money income per capita of the Sughd Region ranks second, behind Dushanbe and RRS. In terms of the industrial output and product exports, the region takes the third position after the Dushanbe and RRS and Khatlon Region. The coefficient of regional efficiency of the Sughd Region was 0.51, which is in third place. Leading positions are occupied by the Dushanbe and RRS (0.68) and Khatlon regions (0.59). The lowest coefficient for GBAR is 0.43 . Table 5 shows the calculation of the competitive advantages of the regions.

Tab. 5 - The system of private indicators of competitive advantages. Source: Authors' calculations

\begin{tabular}{|l|c|c|c|c|}
\hline \multirow{2}{*}{ Private indicators of the region's competitiveness } & \multicolumn{3}{|c|}{ Regions of the Republic of Tajikistan } \\
\cline { 2 - 6 } & SR & $\begin{array}{c}\text { Dushanbe } \\
\text { and RRS }\end{array}$ & KHR & GBAR \\
\hline Foreign investment per capita, USD & 0.97 & 0.04 & 0.10 & 1 \\
\hline
\end{tabular}




\begin{tabular}{|l|c|c|c|c|}
\hline Number of small businesses, units & 0.31 & 1 & 0.04 & 0 \\
\hline $\begin{array}{l}\text { Density of public railways, km of roads per 10,000 } \\
\text { sq. km of territory }\end{array}$ & 0.78 & 1 & 0.07 & 0 \\
\hline $\begin{array}{l}\text { Density of public roads with hard surface, km of } \\
\text { roads per } 1,000 \text { sq. Km. }\end{array}$ & 0.49 & 1 & 0.15 & 0.09 \\
\hline Volume of investments in fixed capital per capita & 0.35 & 1 & 0.91 & 0.82 \\
\hline Coefficient of competitive advantages $\left(\mathrm{T}_{\text {adv }}\right)$ & 0.58 & 0.81 & 0.25 & 0.38 \\
\hline
\end{tabular}

In terms of foreign investment per capita, the Sughd Region is slightly inferior to GBAR. In terms of the number of small enterprises, density of railways and highways, the region occupies the second position, behind only Dushanbe and RRS. In terms of investment in fixed assets per capita, the region ranks fourth after other regions. The coefficient of competitive advantage of the Sughd Region was 0.58, which is in second position after Dushanbe and RS.

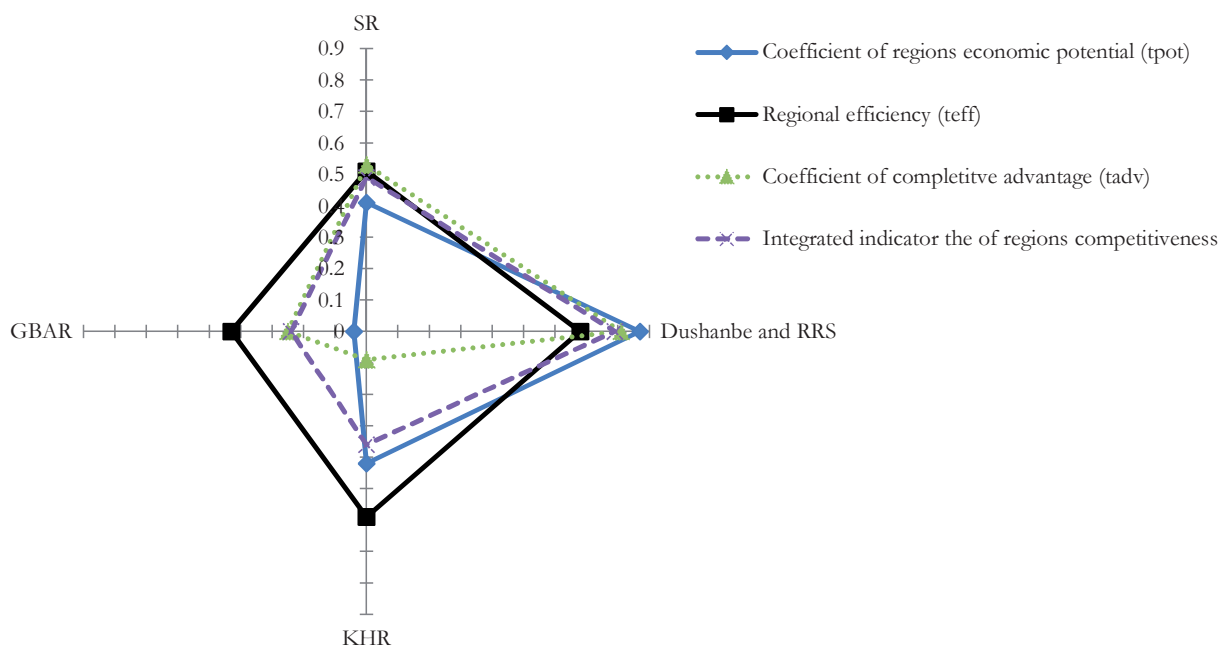

Fig. 1 - Private and integral indicators of competitiveness of the Tajikistan Republic regions. Source: Authors' elaboration

Integral assessment of competitiveness is defined as the arithmetic mean of the obtained estimates. According to the calculation results of the integral indicator, Dushanbe and RRS (0.75) occupy the leading position in the second group of regions with a high level of competitiveness. In second place is the Khatlon Region with 0.49, while the third place belongs to the Sogd Region with 0.47. The Khatlon and Sughd regions belong to the third group of regions with an average level of competitiveness. The last place is occupied by the Gorno-Badakhshan Region - 0.29, which belongs to the fourth group of regions with a low level of competitiveness. Figure 1 graphically presents private and integral indicators regarding the competitiveness of the Republic of Tajikistan regions. 


\section{CONCLUSIONS}

Summarizing the preliminary results, it can be stated that the methodology developed in the course of research allows us to obtain a relative assessment of the region's sustainability, to reflect its place in the aggregate of regions. With a small amount of information, which is necessary for the calculation, the integral indicator has a certain sensitivity and information value. By using it, we can:

- conduct a comparative assessment of sustainability of different territories;

- measure the extent of the economic, social and environmental sustainability of the region;

- identify factors that negatively affect the sustainability of subsystems and the region as a whole;

- more reasonably assess the prospects for region's socio-economic development;

- determine the effectiveness of the use of territory resources;

- identify the directions of socio-economic and environmental activities that are most appropriate for the regional development;

- objectively assess the effectiveness of the work of state authorities in the region and local self-government.

The list of socio-economic indicators used in the calculation of the integral index makes it possible to determine with more authenticity the degree of sustainability of the regional development. The research is based on official data of the state statistics bodies, which ensures their accessibility and comparability. Thus, it can be stated that the sustainability of the country's socio-economic system is possible only if the sustainability of regional systems is ensured.

Scientists propose a significant number of methods to assess the sustainability of socio-economic systems. However, at present, there is no generally accepted methodology. Most of the methods have a number of shortcomings that do not allow making an objective assessment of the sustainability of the system. But, they can serve as a methodological basis for justifying a system of indicators and developing a methodology of assessing the sustainability of a regional socio-economic system.

Based on a study of methods of assessing the competitiveness of the region, the following conclusion can be drawn. To assess the competitiveness of regions, the "Pattern" method could be used. Its advantage lies in the fact that the list of indicators to assess the competitiveness of the region can be changed depending on the specifics and specificity of individual regions, as well as on the existing goals and objectives of the study. This method allows a determination of the level of competitiveness of regions. Based on a study of private indicators, it allows us to determine the competitive advantages and bottlenecks of the regions, which in the future will be the subjects of improvement

\section{References:}

1. Andreev, A.V., Borisova L.M., \& Pluchevskaya E.V. (2008). Bases of regional economy. Russia, Moscow: KNORUS, 334(2), 141-145. 
2. Apargin, N.S., Mymrikova L.S., Zavarina E.S., \& Ryabushkin B.T. (1999). To the question of the concept and content of the system of statistical indicators for the analysis of the socioeconomic development of Russia and its regions. Issues of Statistics, 208(7), 124-126.

3. Fatkhutdinov, R.A. (2005). Strategic competitiveness. ZAO Publishing house Economics. 392(3), 227-235.

4. Garkavaya, V.G. (2015). Integrated assessment of regional development sustainability. Belorussia, Minsk: University of Belorussia. Retrieved from: http://www.rusnauka.com/CCN/ Economics/13_garkavaja.doc.htm.

5. Golubetskaya, N.P. (2005). Indicative approaches to prioritizing investments in entrepreneurial activities in the North-West region of Russia. Economics of the North-West: problems and development prospects, 4(26), 53-65.

6. Granberg, A.G., Busygina, I.M., \& Vvedensky, V.G. (2000). Regional development: the experience of Russia and the European Union. ZAO Publishing house Economics, 435(4), $335-338$.

7. Indicators of sustainable development of the Tomsk region (2004). Print Manufactory, 2(1). $220-228$.

8. Komarova, M.A. (2007). About the criteria of the region's competitiveness. Ways and mechanisms of ensuring the competitiveness of the Russian regions. Russia, Saratov: Povolzhskaya Academy of Public Service. P. A. Stolypin.

9. Merkushev, V.V. (2004). Integral assessment of regional competitiveness. Retrived from http:// sopssecretary.narod.ru.

10. Rosenberg, G.S., Chernikov, S.A., Krasnoshchekov, G. P., Krylov, Yu. M. \& Gelashvili, D. B. (2000). Myths and reality of "sustainable development". Problems of Forecasting, 3(2), 130-154.

11. Seleznev, A.Z. (1999). Competitive positions and infrastructure of the Russian market. Russia, Moscow: Jurist.

12. Shekhovtseva L.S. (2001). Competitiveness of the region: factors and method of creation. Marketing in Russia and abroad, 4(1), 286.

13. Shtulberg, B.M., \& Vvedensky, V.G., (2000). Regional policy of Russia. Theoretical bases, tasks and methods of implementation. Russia: Gemos ARV.

14. Suspitsyn, S.A. (2000). Methodological problems of forecasting priorities and consequences of state regional policy. Journal of Russian Economic, 2(1), 68-79.

15. Suspitsyn, S.A. (2001). Regional programming and territorial differences: opportunities and limitations. Economics and Sociology, 3(1). 97-109.

16. Syroezhin, I.M. (1980). Perfection of the system of indicators of efficiency and quality. Russia, Moscow: Economics. 
Contact information:

Azimova Mashokbida

Khujand Polytechnic Institute of Tajik Technical University

Department of Finance and Credit, Lenin 226, 735700 Khujand

Tajikistan

Email:mashokhon@mail.ru

Avezov Azizullo Khabibovich

Kbujand Polytechnic Institute of Tajik Technical University

Department of Economic Theory and Management,

Lenin 226, 735700 Kbujand

Tajikistan

Email:azizullo@businessconsulting.tj

Premysl Pálka

Tomas Bata University in Zlin

Department of Finance and Accounting

Faculty of Management and Economics, Mostni 5139, 76001 Zlin

Czech Republic

Email:ppalka@fame.utb.cz.

Rakbimi Shakblo

Khujand Polytechnic Institute of Tajik. Tecbnical University

Department of Economic Theory and Management, Lenin 226, 735700 Kbujand

Tajikistan

Email: rabimishablo@mail.ru 